\title{
Discussion on the Strategy of Improving Professional Quality for Vocational Students in the New Era
}

\author{
Xiujuan Dong* \\ TangShan Vocational College of Science and Technology, Tangshan 063000, Hebei, China. \\ E-mail: $422434621 @$ qq.com
}

\begin{abstract}
: with the rapid development of the global economy and the diversification of social structure, the division of work in present social sectors is becoming more and more detailed. The state has put forward higher standards for professional talents in terms of professional quality and employability. With the increasingly fierce competition for employment in society, the situation of higher vocational education is becoming more and more severe. How to change the employment concept and reform the training mode of vocational talents, as well as improve the vocational quality and employability of higher vocational students, has become an urgent problem for educators to explore and solve.
\end{abstract}

Keywords: new era; higher vocational students; professional quality, promotion

\section{Preface:}

In the latest Implementation Plan of Vocational Education Reform, the evaluation of education quality in higher vocational colleges includes students' professional skill level, employment quality and direction, professional ethics, deep cooperation between school and enterprise, and integration of production and education. From this point of view, today, society and enterprises pay more and more attention to the professional quality of graduates and the state has listed the vocational quality education of higher vocational students as one of the key teaching contents. Therefore, higher vocational colleges should rationally analyze the deficiencies of students' professional quality, accurately position the new standards of students' professional quality under the background of innovation and entrepreneurship in higher vocational colleges, so as to reform the new mode of talent cultivation and effectively avoid the imbalance of students' professional quality and knowledge and skills.

\section{The significance of cultivating vocational students' professional quality in the new era}

\subsection{Promoting students' employment and realizing social value}

The ultimate goal of higher vocational education is to achieve employment and improve employment rate. Promoting employment is the fundamental responsibility of the society for higher vocational colleges. Only by making students lay a solid employment foundation in the final stage of life education can students create social values and realize their own ideals. In recent years, with the increasing number of graduates of higher education in China is increasing year by year, the competition between society and enterprises as well as employment situation of students are becoming more and more fierce. Therefore, it is necessary to strengthen the cultivation of vocational students' professional quality, so as to improve their overall quality, communicative ability, organizational ability and professionalism. It is also necessary to promote their good professional skills with moral habits.

\subsection{Improving the quality of students and promoting the development of Education}

Copyright (C) 2020 Xiujuan Dong

doi: 10.18282/le.v9i6.1309

This is an open-access article distributed under the terms of the Creative Commons Attribution Non-Commercial License

(http://creativecommons.org/licenses/by-nc/4.0/), which permits unrestricted non-commercial use, distribution, and reproduction in any medium, provided the original work is properly cited. 
According to the current situation of higher vocational education, there are some differences between the self-cultivation of higher vocational students and the employment demand of enterprises. Because higher vocational colleges do not pay attention to the vocational quality education of students while in the environment of market economy, enterprises pay more attention to the professional quality of employed personnel. Therefore, it is urgent to make great efforts to improve students' professional quality, only by improving their professional quality and self quality can we promote the sustainable development of higher vocational education[1]. Under the background of the new era, the new professional concept and occupation demand are constantly upgrading. The traditional professional concept of "guaranteed distribution" and "iron rice bowl" has long ceased to exist. Only by self-improvement of personal professional knowledge and skills and professional ethics can students achieve employment. Thus, , higher vocational colleges should strengthen the promotion of students' professional quality, so that students can establish a correct employment concept, in order to achieve the development of higher vocational education, and promote synchronous improvement for students from professional ability to professional quality.

\section{Strategies of Improving vocational students' professional quality in the new era}

\subsection{Employment oriented cultivation of students' professional quality}

Higher vocational colleges should take employment as the guidance to cultivate students' professional quality, so as to meet the needs of innovation and entrepreneurship, and establish professional quality education mode. In the aspect of curriculum construction, we should increase the cultivation content of students' recessive professional quality in professional courses and basic courses. Higher vocational colleges should encourage students to participate in professional community activities, and cultivate their own communication skills, team cooperation ability and other professional qualities through practice; they can also carry out more innovative thinking and ability improvement training courses, so as to cultivate students' creativity and practicality, improve their professional ability, and meet the needs of enterprises for higher vocational students' employability.

At the same time, professional teachers should increase the teaching of enterprise workflow, development system and other related content, so that students can understand enterprise operation knowledge in advance and deepen professional understanding. Higher vocational colleges can also add some social adaptability courses as elective courses, such as social communication etiquette, interpersonal relationship management, etc., in order to make students understand the workplace environment in advance.

In addition, higher vocational colleges also need to strengthen school enterprise cooperation to build a real career environment for students, and establish a practical training base on campus, so as to attract enterprises to the school. Qualified higher vocational colleges can also establish and develop the real economy according to their own professional advantages and set up real industries for production and operation, internship and training, subject research and development, as well as social services etc., so as to realize the development of running industries with specialties and development of specialties with industries. It enables students to enter the real work situation in advance by this mode of school enterprise cooperation and understand the workplace demand with competition, so as to make students prepare for graduation and employment as soon as possible, and form a correct career outlook as soon as possible.

\subsection{Taking class culture construction as an important means}

Class culture construction is a kind of soft cultural environment, which is created by teachers and students together and influence students' behavior imperceptibly. The construction of class culture in higher vocational colleges should take into account the characteristics of disciplines and specialties, so as to integrate into the enterprise culture, and realize the integration of specialty and industry. The construction of class civilization is the core of cultural construction, which is the conduct of all students and the pillar of civilized spirit. Teachers should actively guide students to form class training with professional characteristics by fully combining professional characteristics. Students' awareness of communication and cooperation as well as collective cohesion are enhanced by carrying out class activities. In order to improve the overall spirit of the class, teachers should take the construction of class atmosphere as the core 
content of class culture construction from the beginning to the end, collect more successful experience of employment and entrepreneurship of previous graduates, or invite these graduates to return to school to carry out employment and entrepreneurship experience lectures, so that students can fully understand their major employment situation and frontier development trends of the industry [2]. Most of the students in higher vocational colleges have poor self-discipline awareness and bad behavior habits. Therefore, higher vocational colleges should establish an adaptive management mechanism to restrain students' bad behavior habits in their daily study and life, and improve their behavior awareness and discipline concept. Thus, teachers should start from the basic class culture construction, through the good behavior norms of most students to render and influence other students, in or der to finally improve the professional quality of the whole class.

\subsection{Actively organizing students to participate in professional skills competition}

In order to improve the graduates' adaptability to employment and integration into society and enterprises better and faster, higher vocational colleges should organize more professional skills competitions and encourage students to participate actively, which has a positive role in promoting students to cultivate solid professional skills, rich knowledge structure and good professional quality. Students' experience of competition can show their professional skills and spiritual outlook, and cultivate students' professional quality imperceptibly by promoting learning through competition. Students participate in the professional skills competition and operate according to the requirements of the competition. Through the competition, not only students' usual professional skills, but also their professional spirit of pursuing excellence, as well as the ability of on-site emergency handling and team cooperation can be shown, so as to further improve their professional quality in the competition. It is understood that most of the students in higher vocational colleges lack of career planning and psychological preparation, which is easy to lead to employment confusion, and a few of them are afraid of employment. If students take part in more professional skills competitions during school, it is of practical significance for students to improve their psychological quality, adaptability, cooperation ability and problem-solving ability. It is also necessary to cultivate students' innovative spirit, employment ability and professionalism.

\subsection{The teaching content should adapt to the background of entrepreneurship and innovation}

In the face of the new situation in the new era, higher vocational colleges should actively change teaching ideas to ensure that the students meet the needs of entrepreneurship and innovation. We should focus on cultivating students' comprehensive ability and quality and integrating innovative ideas, entrepreneurial ability, entrepreneur quality and other aspects into the vocational talent training plan and program, and gather the strength of all professional and basic courses teachers to cultivate students' professional quality, and promote the development of students' professional quality in order to make incremental benign development for students. At the same time, higher vocational colleges should create opportunities for teachers' professional research and teaching training, in this way, teachers can participate in enterprise training and master the real business process of enterprises so as to provide targeted practical teaching for students. In this process, teachers themselves should explore the development needs of entrepreneurship and innovation education to ensure that the content of vocational quality education is consistent with the needs of entrepreneurship and innovation in the new era, in order to help students achieve personal goals in the future career development.

\subsection{Always guiding education by carrying out moral education and socialist core values to guide education}

Under the background of the new era, higher vocational colleges should always carry out the educational tenet of moral education and moral education first, and cultivate qualified socialist successors by grasping the basic direction of moral education. The main line of education for students should be based on the implementation of socialist core values, so as to guide students to build rich spiritual and cultural connotation with enhancement of their personal ideals and beliefs. With the help of Marxist viewpoint and stand, students establish the correct three outlooks and integrate core values into the teaching process. By the sense of mission and responsibility in the new period, students establish patriotic and professional spirit and enhance self-consciousness, self-restraint, self-management as well as self-improvement, in order to strive to become a practitioner of socialist core values. 


\section{Conclusion}

In a word, higher vocational college education focuses on the cultivation of students' professional knowledge and skills, as well as the overall education with strong professionalism and practicality. However, in order to adapt to the fierce employment competition environment in the new era, the cultivation of students' professional quality should be the top priority. Therefore, in the process of education and teaching in higher vocational colleges, it is necessary to guide students to form correct professional ideas and attitudes based on the cultivation of students' vocational skills. It is also necessary to explore the effective integration of various education and professional quality training, to actively improve the professional quality training system, and lay a solid foundation for the cultivation of professional talents with both political integrity and ability.

\section{References}

1. Xie Dajing. Approaches and Methods of Vocational Quality Training in Higher Vocational Colleges in the New Era. Journal of Hubei Open Vocational College,2019,32(23):34-35.

2. Qin Yongting, Li Guangzi, Zhang Dongmei. Research on the Strategy of Improving Vocational College Students' Professional Quality in the New Era. Journal of Heilongjiang Teachers Development College,2020,39(7):55-57.

3. Pan Yuan, Li Yan. Professional Quality Cultivation and Employment Competitiveness Enhancement for Students. Journal of Chengde Vocational College ,2019,24(3):92-95. 